\title{
Influence of N-glycosylation on Expression and Function of Pseudorabies Virus Glycoprotein gB
}

\author{
Melina Vallbracht (D), Barbara G. Klupp and Thomas C. Mettenleiter*(D) \\ Institute of Molecular Virology and Cell Biology, Friedrich-Loeffler-Institut, 17493 Greifswald-Insel Riems, \\ Germany; Melina.Vallbracht@fli.de (M.V.); barbara.klupp@fli.de (B.G.K.) \\ * Correspondence: thomas.mettenleiter@fli.de; Tel.: +49-383-517-1250
}

Citation: Vallbracht, M.; Klupp, B.G.; Mettenleiter, T.C. Influence of N-glycosylation on Expression and Function of Pseudorabies Virus Glycoprotein gB. Pathogens 2021, 10, 61. https://doi.org/10.3390/ pathogens10010061

Received: 14 December 2020 Accepted: 7 January 2021 Published: 12 January 2021

Publisher's Note: MDPI stays neutral with regard to jurisdictional clai$\mathrm{ms}$ in published maps and institutional affiliations.

Copyright: (C) 2021 by the authors. Licensee MDPI, Basel, Switzerland. This article is an open access article distributed under the terms and conditions of the Creative Commons Attribution (CC BY) license (https:// creativecommons.org/licenses/by/ $4.0 /)$.

\begin{abstract}
Envelope glycoprotein ( $\mathrm{g}$ )B is conserved throughout the Herpesviridae and mediates fusion of the viral envelope with cellular membranes for infectious entry and spread. Like all viral envelope fusion proteins, $\mathrm{gB}$ is modified by asparagine $(\mathrm{N})$-linked glycosylation. Glycans can contribute to protein function, intracellular transport, trafficking, structure and immune evasion. $\mathrm{gB}$ of the alphaherpesvirus pseudorabies virus (PrV) contains six consensus sites for N-linked glycosylation, but their functional relevance is unknown. Here, we investigated the occupancy and functional relevance of N-glycosylation sites in $\operatorname{PrV}$ gB. To this end, all predicted N-glycosylation sites were inactivated either singly or in combination by the introduction of conservative mutations $(\mathrm{N} \rightarrow \mathrm{Q})$. The resulting proteins were tested for expression, fusion activity in cell-cell fusion assays and complementation of a gB-deficient PrV mutant. Our results indicate that all six sites are indeed modified. However, while glycosylation at most sites was dispensable for $\mathrm{gB}$ expression and fusogenicity, inactivation of N154 and N700 affected gB processing by furin cleavage and surface localization. Although all single mutants were functional in cell-cell fusion and viral entry, simultaneous inactivation of all six $\mathrm{N}$-glycosylation sites severely impaired fusion activity and viral entry, suggesting a critical role of $\mathrm{N}$-glycans for maintaining gB structure and function.
\end{abstract}

Keywords: herpesvirus; pseudorabies virus; glycoprotein B; membrane fusion; N-linked glycosylation; virus entry

\section{Introduction}

Herpesviruses are large-enveloped double-stranded DNA viruses that include many important human and animal pathogens. Members of the Alphaherpesvirinae subfamily have the broadest host range, are neurotropic and can persist in the infected hosts for life [1]. In addition to the human herpes simplex viruses 1 and 2 (HSV-1, -2) and Varicella zoster virus (VZV), this subfamily contains many economically important veterinary pathogens such as the Varicellovirus Pseudorabies virus (PrV, Suid alphaherpesvirus 1). PrV is the causative agent of Aujeszky's disease in swine and is capable of causing lethal disease in a variety of other mammalian species [2,3].

Infectious entry and spread of herpesviruses require the fusion of the viral envelope with the host cell membrane. Whereas many enveloped viruses encode a single but multifunctional glycoprotein (g) for host-cell receptor-binding and membrane fusion [4], herpesviruses utilize a multiprotein machinery to mediate these processes. The so-called "core-fusion machinery" which is conserved in all herpesviruses is formed by gB, the bona fide fusion protein, and the heterodimeric complex of the membrane-bound $\mathrm{gH}$ and anchorless $\mathrm{gL}(\mathrm{gH} / \mathrm{gL})$ [5]. In addition to the core-fusion machinery, herpesviruses require the assistance of nonconserved subgroup-specific receptor-binding proteins such as gD of the Alphaherpesvirinae for entry [6-8].

Herpesvirus-mediated membrane fusion is a highly regulated process whose molecular details remain incompletely understood. The current model for alphaherpesvirus 
entry proposes that $\mathrm{gD}, \mathrm{gH} / \mathrm{gL}$ and $\mathrm{gB}$ drive membrane fusion in a cascade-like, $\mathrm{pH}$ independent fashion [9-11]. Binding of $\mathrm{gD}$ to an appropriate host cell receptor, such as nectin-1 or herpesvirus entry mediator (HVEM), serves as the initial fusion trigger [12,13]. A conformational change in receptor-bound $\mathrm{gD}$ is proposed to allow its crosstalk with $\mathrm{gH} / \mathrm{gL}$, possibly by direct interaction between their ectodomains [14]. The gH/gL complex is believed to function as a fusion regulator and, upon triggering, is thought to activate $\mathrm{gB}$, the sole fusion executor $[5,9,11,15]$. Although the exact molecular mechanism of $\mathrm{gB}$ fusion activation by $\mathrm{gH} / \mathrm{gL}$ is unclear, direct interactions between the respective ectodomains and/or cytoplasmic domains have been reported to be essential for fusion activation [16,17]. Activated $\mathrm{gB}$ is proposed to facilitate fusion by refolding from a trimeric metastable high-energy pre-fusion conformation to a stable post-fusion state. During the fusogenic conformational change, $\mathrm{gB}$ exposes two internal fusion loops that interact with the target membrane [18]. The subsequent fold-back process into the energetically more favorable post-fusion conformation juxtaposes the viral and cellular membranes, ultimately leading to their fusion [5].

$\mathrm{gB}$ is the most highly conserved component of the herpesvirus fusion machinery and exhibits around 50\% amino acid (aa) sequence identity within each subfamily [5]. High-resolution crystal structures of the stable post-fusion state have been determined for gB ectodomains of five different herpesviruses, including PrV [18,19], HSV-1 [20], and VZV [21], all revealing rod-shaped trimers which are composed of five domains (DI-V) per protomer (Figure 1). Based on these structural studies, gB was identified as a class III fusion protein [22]. In contrast to the well-characterized post-fusion conformation, structural information on the $\mathrm{gB}$ pre-fusion conformation is limited to HSV-1 $[23,24]$ and the betaherpesvirus human cytomegalovirus (HCMV) gB [25].

The majority of viral envelope proteins, including herpesvirus $\mathrm{gB}, \mathrm{gH}$ and $\mathrm{gD}$, are modified by asparagine (N)-linked glycosylation, which can play crucial roles in correct folding, trafficking, function and immune evasion [28-30]. N-glycosylation starts in the endoplasmic reticulum (ER) with the en bloc attachment of oligosaccharides to the asparagine side chain in $\mathrm{N}-\mathrm{X}$-threonine $(\mathrm{T})$ or -serine $(\mathrm{S})$ sequons of the nascent polypeptide chain $(\mathrm{X}$ represents any amino acid except proline) [31]. Following the linkage of high mannose-type glycans to $\mathrm{N}$ of each sequon in the ER, glycan maturation takes place in the Golgi apparatus. Glycan processing involves trimming of glucose and mannose residues and subsequent addition of various terminal sugars resulting in different classes of glycans, including high mannose, hybrid and complex N-glycans [28,32]. Functional and structural studies on $\mathrm{N}$-linked glycans from several viral fusion proteins, including influenza hemagglutinin [33,34], coronavirus spike protein [35-38], Ebola virus glycoprotein GP [39], envelope glycoprotein (Env) of human immunodeficiency virus-1 (HIV-1) [40,41], or envelope (E) protein of the flaviviruses Zika [42] and Dengue virus [43] have shown that these structures can play diverse functional and structural roles, e.g., in immune evasion by shielding from neutralizing antibodies, enhancement of infection, or stability and maturation of the respective fusion protein.

Recently, we have investigated the occupancy and functional relevance of N-glycosylation sites in $\mathrm{PrV}$ gH, highlighting a modulatory but non-essential role of $\mathrm{N}$-linked glycans for $\mathrm{gH}$ function during membrane fusion [30]. In contrast to $\mathrm{gH}$, there is only limited information on the role of N-linked glycans on $\mathrm{gB}$. In fact, the only $\mathrm{gB}$ homolog tested for the role of all predicted N-linked glycans is HSV-2 gB [29]. Therefore, in the present study, we set out to expand our analyses to the N-linked glycans in $\operatorname{PrV~gB.~PrV~gB~contains~six~potential~}$ $\mathrm{N}$-glycosylation sites, all located in the ectodomain. Occupation of three predicted sites by N-glycans (N264 in DI, N444 in DII, N636 in DIV) was confirmed by crystal structure analysis of the $\operatorname{PrV} \mathrm{gB}$ post-fusion ectodomain, but their functional relevance is unknown. 

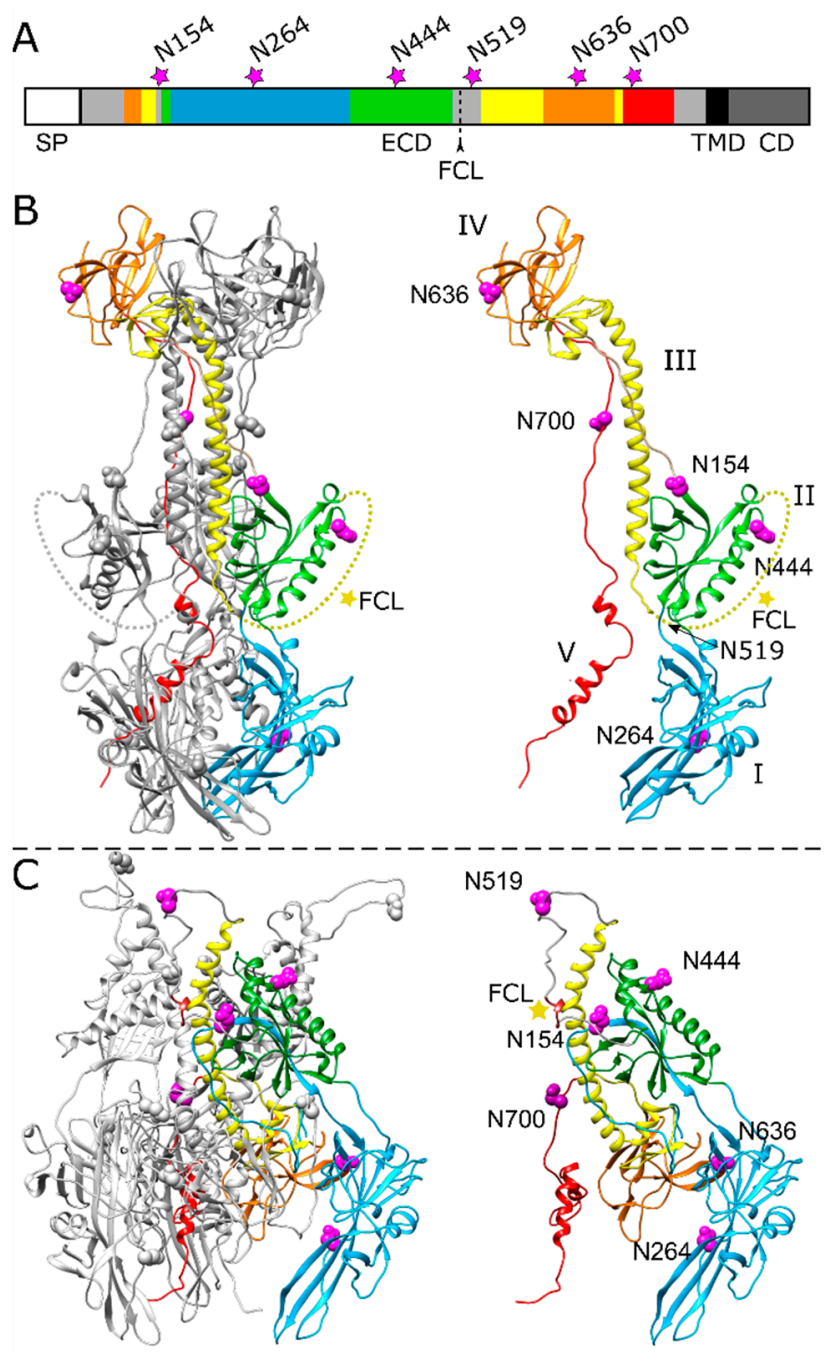

Figure 1. Position of potential N-linked glycosylation sites in the PrV gB ectodomain. (A) Schematic diagram of $\operatorname{PrV}$ gB with the signal peptide (SP), ectodomain (ECD), transmembrane domain (TMD) and a cytoplasmic domain (CD) indicated. The five domains (DI-V) forming the ectodomain are colored in blue (DI), green (DII), yellow (DIII), orange (DIV) and red (DV) according to the ribbon diagrams in $(\mathbf{B}, \mathbf{C})$, and regions not resolved in the post-fusion structure are depicted in grey. Position of the furin-cleavage site (FCL) and the potential asparagine (N)-linked glycosylation sites N154, N264, N444, N519, N636 and N700 are indicated. (B) Ribbon diagram of the PrV gB post-fusion trimer (PDB ID: 6ESC) [18], (left panel) and the monomer (right panel) is shown. Domains I-V of one protomer are highlighted in different colors, and the predicted glycosylation sites are indicated by purple spheres. N519 lies within a flexible region (dotted yellow line) that was not solved in the crystal structure and is marked by an arrow. The yellow star indicates the furin-cleavage site. (C) Model of pre-fusion PrV gB trimer (left panel) was generated using the protein structure homology-modeling server SWISS-MODEL [26] and the pre-fusion structure of HSV-1 gB as template [24]. Domains I-V of one protomer (right panel) are colored as in (A,B), and the predicted glycosylation sites are shown as purple spheres, and the furin-cleavage site is marked by a yellow star. The structure images were generated using UCSF Chimera (version 1.13.1) [27].

To investigate the significance of $\mathrm{N}$-glycosylation on $\operatorname{PrV} \mathrm{gB}$, we systematically inactivated all six potential sites by the introduction of a conservative mutation in the individual sequons in the plasmid cloned gB gene (UL27), resulting in the replacement of asparagine (N) by glutamine (Q). Resulting gB mutants were tested for correct expression and glycosylation as well as fusogenicity in a virus-free transfection-based cell-cell fusion assay [44]. 
In addition, the ability of the gB variants to function in virus entry was investigated by transcomplementation of a gB-deficient PrV mutant.

\section{Results}

\subsection{Effect of N-Glycosylation Site Mutations on $g B$ Processing and Expression}

The amino acid sequence of PrV gB strain Kaplan (Ka) contains six potential Nlinked glycosylation sites matching the consensus motif $\mathrm{N}-\mathrm{X}-\mathrm{T} / \mathrm{S}$, where $\mathrm{X}$ represents any amino acid (aa) except proline [31]. All predicted N-glycosylation sites map to the gB ectodomain (Figure 1). The three sites at aa positions N154, N264, N444 reside within the N-terminal subunit of furin-cleaved gB, while sites N519, N636 and N700 are located within the C-terminal subunit (Figure 1A-C). Crystal structure analysis of the PrV gB postfusion ectodomain expressed in insect cells revealed occupation of three $\mathrm{N}$-glycosylation sites, namely N264 in domain I (DI), N444 in DII and N636 in DIV [18]. Based on the recently published pre-fusion structure of HSV-1 gB, a model of PrV pre-fusion gB was generated using the protein structure homology-modeling server SWISS-MODEL [26], and the N-glycosylation sites were mapped into the structure (Figure 1C). For further analysis, the $\mathrm{N}$ codon of each sequon was replaced by a glutamine codon $(\mathrm{N} \rightarrow \mathrm{Q})$ via site-directed mutagenesis of the $\mathrm{gB}$ expression plasmid. The resulting $\mathrm{gB}$ expression plasmids were used for in vitro expression, transient-transfection-based fusion assays and trans-complementation studies.

The occupancy of the individual N-glycosylation sites and processing of the different $\mathrm{gB}$ mutants was investigated by Western blot analyses of cell lysates from rabbit kidney (RK13) cells transfected with expression plasmids for gB wild-type (WT) and the different $\mathrm{N}$-glycosylation site mutants. Fully glycosylated $\operatorname{PrV} \mathrm{gB}$ is an approx. 120-kDa polypeptide that undergoes proteolytic processing by cellular furin in the Golgi apparatus $[45,46]$. The protease recognizes the basic sequence ${ }^{501} \mathrm{RRARR}^{505}$, located in a flexible loop that connects gB DII and DIII (Figure 1). Cleavage after R505 generates two subunits, gBb $(\sim 69-\mathrm{kDa})$ and $\mathrm{gBc}(\sim 58-\mathrm{kDa})$, which remain linked by disulfide bonds. To visualize $\operatorname{PrV} \mathrm{gB}$ in Western blot analyses two monoclonal antibodies ( $\mathrm{mAb})(\mathrm{c} 15-\mathrm{b} 1$ and $\mathrm{A} 20-\mathrm{c} 26)$ were used that detect either the $\mathrm{N}$-terminal ( $\mathrm{gBb}, \mathrm{c} 15-\mathrm{b} 1)$ or the C-terminal subunit ( $\mathrm{gBc}, \mathrm{A} 20-\mathrm{c} 26)$, respectively (Figure 2) [18,47].

As expected, two bands were observed for PrV WT gB, corresponding to the uncleaved $\mathrm{gB}$ precursor $(\mathrm{gBa})$ and the $\mathrm{N}$-terminal subunit $(\mathrm{gBb})$ when $\mathrm{mAb} \mathrm{c} 15-\mathrm{b} 1$ was used (Figure 2A, upper panel), or the C-terminal subunit $(\mathrm{gBc})$ when blots were probed with A20-c26 (Figure 2A, lower panel). The mutants revealed WT-like behavior in processing by furin with the exception of gB-N154Q and gB-N700Q (Figure 2A). These variants showed only low levels of the furin-cleaved subunits and a more abundant signal for the uncleaved gB precursor indicating that N154Q and N700Q affected furin-cleavage (Figure 2). Inactivation of the N-glycosylation sites at N264 and N444 resulted in a shift of the N-terminal subunit $(\mathrm{gBb})$ to a lower molecular mass, indicating that both sites are occupied. Differences in the molecular weight between $\mathrm{gBb}$ of the two single mutants gB-N264Q and gB-N444Q suggested differences in the added N-glycans (Figure 2A, upper panel). For N519Q or N636Q, which are located in the C-terminal subunit, higher electrophoretic mobility of the respective gBc could be observed when compared to WT gB (Figure 2A, lower panel). These results indicate that gB positions N264, N444, N519 and N636 are occupied by N-glycans. Mutation of the N-glycosylation site N700Q and, to a lesser extent, N154Q had an impact on $\mathrm{gB}$ processing by cellular furin.

In addition, a gB variant was generated in which all six $\mathrm{N}$-glycosylation sites were inactivated simultaneously (gB-N6xQ). Cell lysates of gB-N6xQ expressing RK13 cells were treated with peptide-N-glycosidase $\mathrm{F}$ (PNGase F), which removes all N-linked carbohydrates. Similar to the single mutant $\mathrm{gB}-\mathrm{N700Q}$, only the uncleaved $\mathrm{gB}$ precursor could be observed for gB-N6xQ. However, unlike PrV gB WT, gB-N6xQ was not sensitive to PNGase $\mathrm{F}$ treatment and revealed a similar apparent molecular mass as gBa of PNGase F gB WT 
(Figure 2B). Overall, these results show that all predicted N-glycosylation sites on $\operatorname{PrV}$ WT $\mathrm{gB}$ are used and that they are inactivated in $\mathrm{gB}-\mathrm{N} 6 \mathrm{xQ}$.

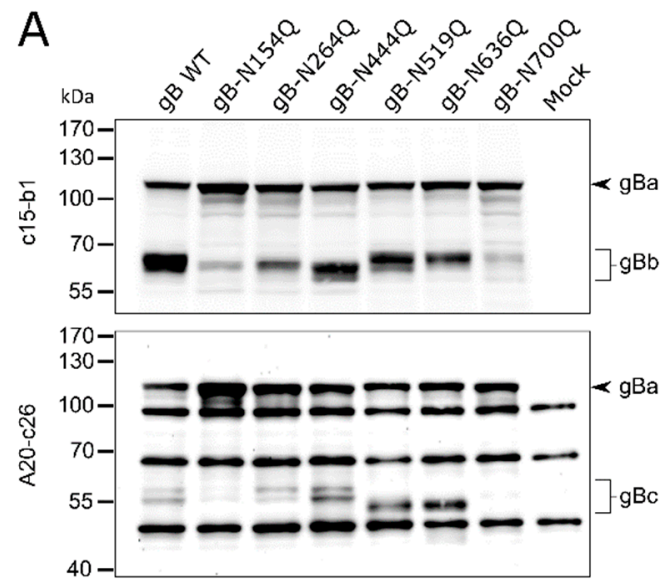

B

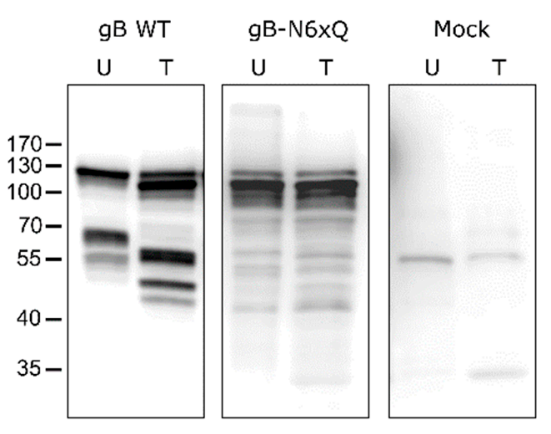

Figure 2. Expression and glycosylation analysis of PrV gB N-glycosylation mutants. (A) Lysates of RK13 cells transfected with expression plasmids for the indicated $\mathrm{gB}$ variants were separated by SDS-PAGE under reducing conditions. Lysates of cells transfected with empty vector pcDNA-3 served as a negative control (Mock). Blots were either probed with the monoclonal antibody $(\mathrm{mAb}) \mathrm{c} 15-\mathrm{b} 1$, directed against the $\mathrm{N}$-terminal subunit $(\mathrm{gBb})$ of furin-cleaved gB (upper panel), or with mAb A20-c26 (lower panel) recognizing the C-terminal gB subunit (gBc). Signals of uncleaved gB (gBa) or furin-cleaved $\mathrm{gB}$ subunits ( $\mathrm{gBb}$ and $\mathrm{gBc}$ ) are labeled by arrowheads and braces. The molecular masses of marker proteins are indicated. Representative blots from three independent experiments are shown. (B) Analysis of N-linked carbohydrates in gB. Lysates of RK13 cells expressing PrV wild-type (WT) gB or gB-N6xQ were either left untreated (U) or treated (T) with PNGase F. Samples were separated by SDS-PAGE under reducing conditions, and blots were probed with a monospecific rabbit antiserum against PrV. Three independent experiments were performed, and one representative blot is shown.

To investigate the expression and subcellular localization of the different mutants, indirect immunofluorescence analyses of transfected RK13 cells using the polyclonal antigB serum [48] without or after permeabilization were performed (Figure 3). Low levels of surface localization could be observed for PrV WT gB, which is in line with previous results [18]. Fluorescence-activated cell sorting (FACS) analysis revealed that only around $4 \%$ of $\operatorname{PrV~WT~gB~is~presented~at~the~plasma~membrane~(data~not~shown),~complicating~}$ robust quantitation. Surface localization of gB-N264Q, -N444Q, -N519Q and -N636Q was similar to WT gB. However, no staining could be detected without permeabilization for mutants gB-N154Q, gB-N700Q or gB-N6xQ, indicating that gB N-glycosylation at N154 and N700 is not only important for processing by cellular furin but also for gB surface localization.

\subsection{In Vitro Fusion Activity of $g B N$-Glycosylation Mutants}

To investigate the role of the six N-glycosylation sites for $\mathrm{gB}$ function during membrane fusion, the different mutants were tested in a transient transfection based cell-cell fusion assay [44]. This assay exploits the ability of the herpesvirus entry glycoproteins $\mathrm{gB}, \mathrm{gH} / \mathrm{gL}$ and $\mathrm{gD}$ to mediate cell-cell fusion in the absence of other viral components, thereby allowing for more direct analysis of $\mathrm{gB}$ function during fusion than in the viral context (Figure 4). 


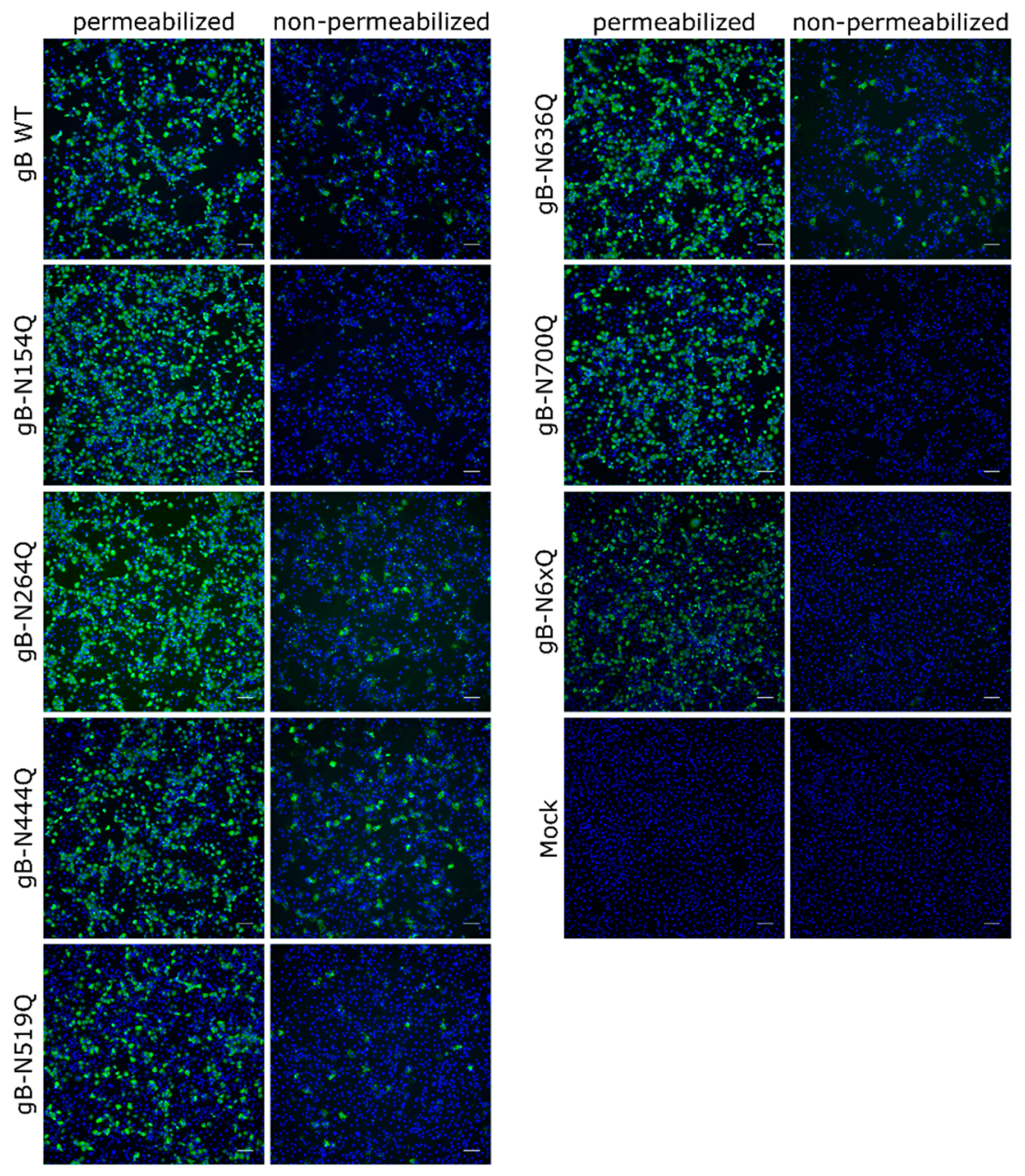

Figure 3. Subcellular and surface expression of the PrV gB N-glycosylation mutants. RK13 cells were transfected with expression plasmids for wild-type (WT) gB or the indicated gB mutants. One day after transfection, cells were fixed and either permeabilized or not. $\mathrm{gB}$ was detected using a $\mathrm{gB}$ specific rabbit antiserum and Alexa Fluor 488-conjugated secondary antibodies. Nuclei were stained with Hoechst. Total and cell surface expression of $\mathrm{gB}$ was analyzed by fluorescence microscopy (Nikon Eclipse Ti-S). Scale bars: $100 \mu \mathrm{m}$. Representative images from three independent experiments are shown.

Fusion activities of the different $\mathrm{gB}$ mutants in combination with $\mathrm{gH} / \mathrm{gL}$ and $\mathrm{gD}$ were determined $24 \mathrm{~h}$ after cotransfection of RK13 cells with the respective expression plasmids and enhanced green fluorescent protein (EGFP), which was used as a marker to visualize syncytia formation. The area and number of syncytia within 10 fields of view ( $5.5 \mathrm{~mm}^{2}$ each) were determined, and the mean syncytia area was multiplied by the number of syncytia to obtain the absolute fusion activity. Fusion activity of the four wild-type proteins served as positive control and was set as $100 \%$, while empty vector pcDNA-3 was substituted for the $\mathrm{gB}$ expression plasmid and used as a negative control. Although inactivation of N154 or N700 affected furin-cleavage and surface localization of gB as evident from Western blot analyses and immunofluorescence analyses (Figures 2A and 3), all mutants revealed wild-type like fusion activities (Figure 4). In contrast, simultaneous inactivation of all N-glycosylation sites severely affected $\mathrm{gB}$ fusogenicity. Fusion activity of gB-N6xQ was almost reduced to background levels (Figure 4), suggesting that N-glycans may be important for the overall $\mathrm{gB}$ structure and/or stability of the protein. 


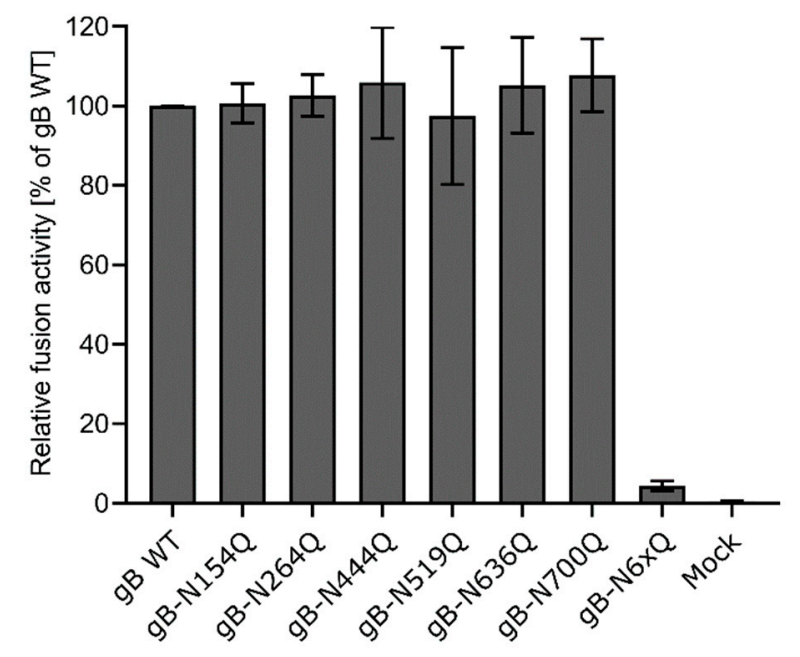

Figure 4. Cell-cell fusion activity of gB N-glycosylation site mutants. RK13 cells were cotransfected with $200 \mathrm{ng}$ of the expression plasmids for enhanced green fluorescent protein (EGFP), PrV gH, gL, $\mathrm{gD}, \mathrm{gB}$ wild-type (WT) or the indicated gB glycosylation site mutant. Cells transfected with EGFP and empty vector pcDNA-3 served as a mock control. $24 \mathrm{~h}$ post-transfection, syncytia formation was assessed. The number of syncytia in 10 fields of view was multiplied by the corresponding mean syncytia area to obtain the total fusion activity. Fusion activities were normalized to activities obtained with the four wild-type glycoproteins. Mean relative values from four independent experiments and corresponding standard deviations are shown.

\subsection{Impact of gB N-Glycosylation Site Mutations on Virus Entry}

The ability of the gB mutants to function in virus entry was investigated by complementation of a PrV mutant lacking the gB gene UL27 (PrV- $\Delta \mathrm{gB}$ ) [47]. To this end, RK13 cells were transfected with expression plasmids for either WT gB, the different gB mutants or with the empty vector pcDNA-3, which served as a negative control. One day posttransfection, cells were infected with trans-complemented PrV- $\Delta \mathrm{gB}$ at an MOI of 3 . After $24 \mathrm{~h}$, cells and supernatants were harvested, and progeny virus titers were determined on RK13 cells stably expressing PrV gB WT (RK13-gB) [47]. In line with the results from cell-cell fusion assays, all $\mathrm{gB}$ mutants with a single inactivated $\mathrm{N}$-glycosylation site were able to efficiently complement the gB-deficient $\operatorname{PrV}$ mutant to titers comparable to WT gB (Figure 5). In contrast, complementation by gB-N6xQ resulted in severely reduced titers of only approximately $5 \times 10^{2} \mathrm{PFU} / \mathrm{ml}$. However, although very low, titers of gB-N6xQ complemented $\operatorname{PrV}-\Delta g B$ were still above background levels (Figure 5 ), indicating a residual level of $\mathrm{gB}$ fusion activity even in the absence of all N-linked glycans.

\section{Discussion}

Host-cell-derived N-linked glycans on viral envelope proteins can influence protein folding and stability, transport, viral entry and spread, and immune evasion [49]. Recently, we investigated the functional relevance of N-linked glycosylation in $\mathrm{PrV} g \mathrm{gH}$ [30]. In the present study, we extended our analyses to N-linked glycans on $\operatorname{PrV} g B$. To this end, the six predicted N-glycosylation sites in PrV gB (N154, N264, N444, N519, N636 and N700) (Figure 1) were systematically inactivated by conservative mutation $(N \rightarrow Q)$. The resulting single mutants and a gB mutant with inactivation of all six predicted sites were tested for proper expression, processing, and function in cell-cell fusion and viral entry.

Comparative sequence analyses reveal that three out of six sites in $\operatorname{PrV} g B$, namely N154, N444 and N700, are conserved among alphaherpesvirus gBs, N519 is not present in BoHV-1, N636 is conserved in members of the Varicellovirus genus, and N264 has only a counterpart in VZV (Figure 6). 


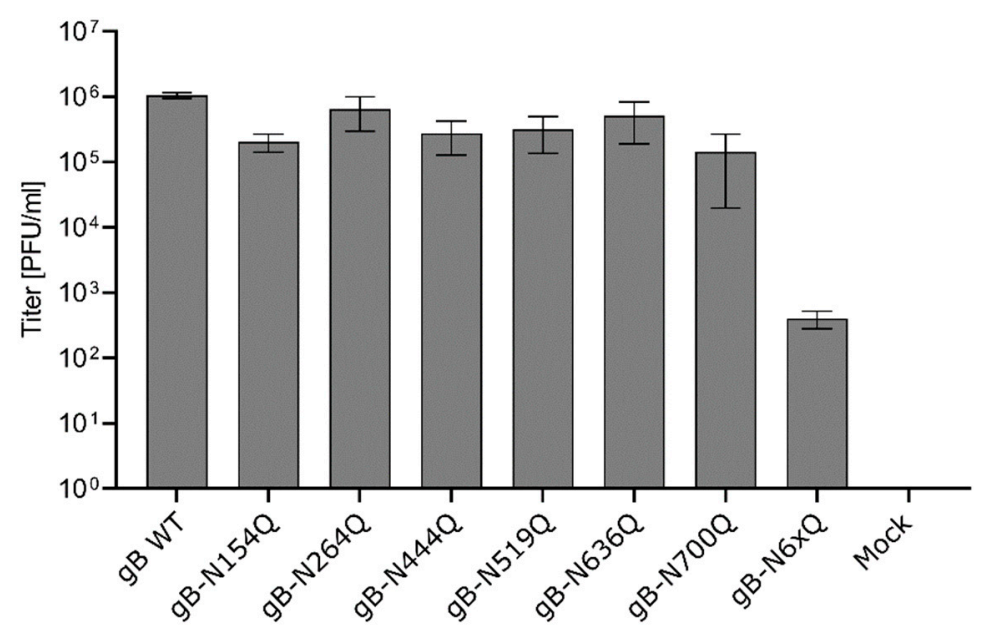

Figure 5. Virus entry mediated by the gB N-glycosylation site mutants. RK13 cells were transfected with expression plasmids encoding WT or mutant gB. Cells transfected with an empty vector served as a negative control (Mock). $24 \mathrm{~h}$ later, the cells were infected with PrV- $\Delta \mathrm{gB}$ at an MOI of 3. Progeny virus titers were determined on gB-expressing RK13 cells and are given in plaque-forming units (PFU)/ml. Shown are the mean values from four independent experiments and corresponding standard deviations.

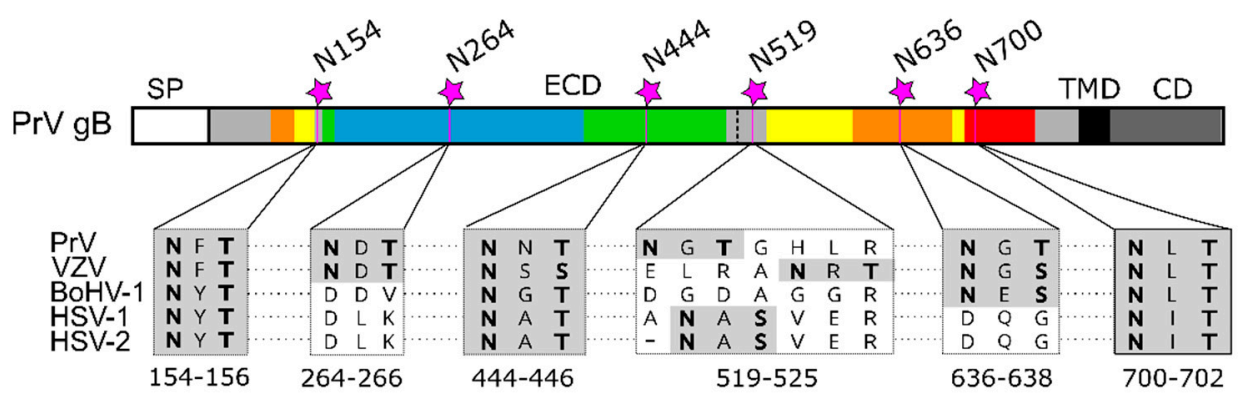

Figure 6. N-glycosylation sites in alphaherpesvirus gB. Schematic representation of the $\operatorname{PrV}$ gB open reading frame colored and labeled as in Figure 1A. N-linked glycosylation sites N154, N264, N444, N519, N636 and N700 in PrV gB are indicated, and corresponding sequence alignment of the N-X-S/T sequons of gB of pseudorabies virus (PrV; EM64049.1), varicellazoster virus (VZV; AH010537.2), bovine alphaherpesvirus 1 (BoHV-1; KU198480), human alphaherpesvirus 1 (HSV-1, strain F; ADD59998.1), human alphaherpesvirus 2 (HSV-2, strain 333; ABU45421.1) are shown below. The N-X-S/T sequons are shown in boldface on gray background. The sequence alignment was generated using ClustalW (Geneious Prime 2019.2.3).

N154 is the most N-terminally located N-linked glycosylation site in $\operatorname{PrV} \mathrm{gB}$ and maps to a flexible region connecting domains II and III (Figures 1 and 6). Western blot analyses showed that inactivation of this site affected the processing of $\mathrm{gB}$ by cellular furin, as evident by low levels of the two furin-cleaved subunits $\mathrm{gBb}$ and $\mathrm{gBc}$ and a more abundant signal for the uncleaved $\mathrm{gB}$ for this mutant (Figure 2A). Early studies revealed that $\mathrm{gB}$ cleavage occurs in the Golgi apparatus after gB oligomerization in the ER [45]. Herpesvirus $\mathrm{gB}$ is believed to undergo extensive conformational changes for fusion and is reported to transit from a (predicted) trimeric pre- to a trimeric post-fusion form [5]. Only recently, the pre-fusion structure of HSV-1 gB was reported [24]. Here, the HSV-1 pre-fusion gB structure was used as a template to generate a model for pre-fusion PrV gB (Figure 1C). In contrast to the location of aa N154 in the post-fusion conformation (Figure 1B), in the PrV gB pre-fusion model, N154 is positioned in close proximity to the furin-cleavage site (Figure 1C). Thus, it is conceivable that inactivation of this site resulting in the absence of the carbohydrate moiety at N154 may have an influence on the surrounding protein structure, which affects the accessibility for or recognition by furin and results in the observed defect in the cleavage. 
Despite impaired cleavage and cell surface localization (Figure 2A), gB-N154Q was still able to mediate efficient in vitro cell-cell fusion to levels comparable to WT gB (Figure 4). Moreover, this mutant was able to rescue the entry defect of a gB-deficient PrV mutant (PrV- $\Delta \mathrm{gB}$ ) reaching titers similar to WT gB complemented PrV- $\Delta \mathrm{gB}$ (Figure 5). Although proteolytic cleavage is a prerequisite for fusion activity of several viral fusion proteins such as influenza hemagglutinin, paramyxovirus F or retrovirus Env, protease cleavage is not required for fusion activation of $\operatorname{PrV} \mathrm{gB}[18,50]$, which is also true for other class III fusion proteins [51,52]. Thus, our results parallel previous findings that proteolytic cleavage is not required for $\operatorname{PrV} g B$ function [18]. Moreover, the data confirm earlier studies showing that in vitro fusion activity and surface expression of gB do not correlate $[47,53]$. Interestingly, mutation of N133 in HSV-2, which corresponds to PrV gB N154, was similarly shown to affect protein maturation and intracellular trafficking, suggesting a conserved function of this site [29].

Similar to site N154, N700, which is the most C-terminally located gB N-glycosylation site and maps to DV, was found to be important for proper processing by furin and cell surface localization (Figures 2A and 3). Interestingly, site N700 is also conserved in alphaherpesvirus gBs and corresponds to N668 in HSV-2 gB (Figure 6). As observed for N700 in this study, inactivation of glycosylation at N668 impaired processing of HSV-2 gB [29]. However, in contrast to PrV gB in which sites N154 and N700 are apparently dispensable for in vitro fusion (Figure 4) and viral entry (Figure 5), inactivation of the glycosylation sites at N133 or N668 significantly inhibited in vitro fusion and viral entry mediated by HSV-2 gB [29]. These findings highlight similarities but also intriguing differences between $\mathrm{gB}$ of the two viruses.

Differences in the requirements for gB fusion activity exist [5] and early swapping experiments have shown that $\operatorname{PrV}$ gB could complement the lethal defect of a gB-negative HSV-1 mutant, but not vice versa [54]. Moreover, whereas HSV-1 gB induced only very low levels of in vitro cell-cell fusion when coexpressed with $\mathrm{PrV}$ gH/gL and gD, fusion activity observed for PrV gB with the HSV-1 glycoproteins was significantly higher [55]. These experiments indicate that fusion mediated by $\operatorname{PrV} \mathrm{gB}$ is more robust and may require fewer specific interactions than gB of HSV, further suggesting that $\operatorname{PrV} g B$ may be more tolerant of local structural changes.

Two other N-linked glycosylation sites in HSV-2 gB, N390 and N483, have been found to be important for in vitro cell-cell fusion activity and viral entry [29]. However, the site at N390 is conserved only in the simplex viruses, and PrV gB N519, corresponding to N483 in HSV-2 gB (Figure 6), was found to be dispensable for in vitro fusion activity and viral entry of PrV gB (Figures 4 and 5), indicating different roles of this site in $\mathrm{gB}$ of the two viruses. When the study by Luo et al. was conducted [29], the pre-fusion structure of HSV-1 gB was not available. However, in the HSV-1 pre-fusion structure and in the pre-fusion PrV gB model, aa N483 (HSV-2 gB) and N519 (PrV gB) are exposed on the very top of the molecule (Figure 1C). Due to this position, it is tempting to speculate that a glycan attached to this site could play a role in immune evasion.

Western blot analyses indicated that sites N264, N444, N519 and N636 are all occupied by $\mathrm{N}$-glycans since the respective $\mathrm{N}$-terminal $(\mathrm{gBb})$, or $\mathrm{C}$-terminal $(\mathrm{gBc})$ subunits migrated faster compared to the respective WT gB fragments (Figure 2A). Although these sites are apparently all modified by N-glycans in $\operatorname{PrV~gB,~their~presence~is~not~required~for~proper~}$ gB processing, surface localization (Figure 3), function during cell-cell fusion (Figure 4), or viral entry (Figure 5). Nevertheless, they may perform different biological functions in vivo. Interestingly, the three single mutants gB-N154Q, gB-N264Q and gB-N444Q exhibited differences in their respective molecular weights when compared to each other (Figure 2A, upper panel). In particular, gB-N444Q migrated faster than gB-N154Q and gB-N264Q. It is well established that glycoproteins can be heterogeneous in their content of complex N-glycans, whereby the N-glycan diversity may be caused by the aa sequence and/or the local structure influencing substrate availability for Golgi glycosidases or 
glycosyltransferases [56]. Thus, the observed differences in molecular weight may be due to the heterogeneous composition of carbohydrates attached to N444, N154 and N264 [57].

N636 is located in gB DIV and is part of an NXS/T sequon that is conserved among members of the varicelloviruses VZV and BoHV-1 but not in the simplex viruses HSV-1 and 2 (Figure 6). N620 of VZV gB, which corresponds to PrV N636, lies within a conserved beta-strand in DIV, which was recently reported to be part of an epitope recognized by a neutralizing human $\mathrm{mAb}$ (93k) directed against VZV gB [21]. Although inactivation of N636 had no effect on $\operatorname{PrV}$ gB function during cell-cell fusion or viral entry, the relevance of this N-glycosylation site in vivo remains to be determined. In this context, it is well documented that N-glycans of viral surface proteins, e.g., of HIV-1 Env, can interfere with the host antibody response by serving as a "shield" to cover essential epitopes, thereby protecting the virus from antibody-mediated neutralization [58]. At present, we cannot exclude that $\mathrm{N}$-glycans on $\operatorname{PrV} \mathrm{gB}$ could serve to obscure epitopes, which could be targeted by neutralizing antibodies.

In addition to the single mutants, a gB variant was generated in which all $\mathrm{N}$-glycosylation sites were inactivated simultaneously. Glycosylation analysis revealed that this $\mathrm{gB}$ variant is not sensitive to PNGase F digestion (Figure 2B), and gBa bands of PNGase digested and non-treated gB-N6xQ migrated comparable to PNGase F-treated WT gB, indicating that all sites were indeed inactivated in gB-N6xQ (Figure 2B). Western blot (Figure 2B) and indirect immunofluorescence analyses (Figure 3) revealed that gB-N6xQ is neither processed by furin nor detectable on the surface of transfected RK13 cells. Although all single mutants were able to promote WT-like in vitro cell-cell fusion and viral entry, gBN6xQ was incapable of mediating efficient cell-cell fusion, and fusion activity was reduced to almost background levels (Figure 4). In good correlation with these results, gB-N6xQ complemented gB-deficient PrV to only very low titers of $5 \times 10^{2} \mathrm{PFU} / \mathrm{mL}$ (Figure 5). For other components of the herpesvirus fusion machinery, such as HSV-1 gD, it was shown that the absence of $\mathrm{N}$-glycans influences the overall protein structure. However, these structural changes did not affect $\mathrm{gD}$ function during infection in cell culture [59-61]. With respect to this, it is conceivable that the individual mutations in $\operatorname{PrV} \mathrm{gB}$ led to minor structural changes that have no major impact on $\mathrm{gB}$ structure and subsequently $\mathrm{gB}$ functionality. In $\mathrm{gB}-\mathrm{N} 6 \times \mathrm{Q}$, however, the structural changes may have an additive adverse effect on $\mathrm{gB}$ structure, leading to impaired processing and loss of function.

In summary, our results show that all six predicted $\mathrm{N}$-glycosylation sites in $\operatorname{PrV} \mathrm{gB}$ are modified in vitro by $\mathrm{N}$-glycans. We demonstrate that the individual $\mathrm{N}$-glycosylation sites play a modulatory but dispensable role for $\mathrm{gB}$ function, whereas simultaneous inactivation of all sites severely affects $\mathrm{gB}$ function in fusion, highlighting an important role of these glycans for correct folding, structure and/or stability of gB. Although mutation of most of the sites had no notable effect on $\mathrm{gB}$ processing and function during in vitro fusion and entry, which is largely congruent to our results on the role of N-glycans on $\mathrm{PrV}$ gH [30], we found that $\mathrm{N}$-glycosylation of $\operatorname{PrV} \mathrm{gB}$ at the highly conserved positions N154 and N700 is important for proper processing of $\mathrm{gB}$ by cellular furin. Taken together, this study expands our knowledge on the role of N-linked glycans on the herpesvirus fusion protein $\mathrm{gB}$. Which role gB N-glycosylation plays in vivo and whether removal of certain sites can affect virus-specific antibody responses remains to be determined.

\section{Materials and Methods}

\subsection{Cells and Viruses}

Rabbit kidney (RK13) and RK13-gB cells [47] were grown in Dulbecco's modified Eagle's minimum essential medium (MEM) supplemented with $10 \%$ fetal calf serum at $37^{\circ} \mathrm{C}$. Viruses used in this study were derived from PrV strain Kaplan (PrV-WT) [62]. The PrV mutant lacking the $\mathrm{gB}$ gene has been described previously [47]. 


\subsection{Expression Plasmids and Generation of $\operatorname{Pr} V g B N$-Glycosylation Mutants}

Generation of expression plasmids for PrV-WT gB, gD, $\mathrm{gH}$, and $\mathrm{gL}$ has been described previously [63]. The expression plasmid encoding $\operatorname{PrV} \mathrm{gB}$ WT was used for site-directed mutagenesis (QuikChange II XL kit, Agilent, CA Santa Clara, USA). PrV gB residues are numbered according to GenBank accession number AEM6404.1 [64]. The oligonucleotide primers used for $\mathrm{gB}$ mutagenesis leading to inactivation of the potential $\mathrm{N}$-glycosylation sites are listed in Table 1 . Correct mutagenesis was verified by sequencing using the standard primers T7 and SP6 as well as the gB-specific primers 130 and 134 listed in Table 1, the BigDye Terminator v1.1 cycle sequencing kit, and a 3130 genetic analyzer (Applied Biosystems, CA Foster City, USA).

Table 1. Oligonucleotides used for mutagenesis and sequence analyses.

\begin{tabular}{cc}
\hline Primer Name & Sequence $\left(5^{\prime} \rightarrow \mathbf{3}^{\prime}\right)$ \\
\hline gB Ka N154Q F & CTCGCAGGGGCGCCAGTTCACGGAGGGG \\
gB Ka N264Q F & CGGCTGGCACACCACCCAGGACACCTACACC \\
gB Ka N444Q F & CGGCGGCGCTACCAGAACACGCACGTGCTGG \\
gB Ka N519Q F & CGCCGGCCGTCCAGGGCACGGGGCACC \\
gB Ka N636Q F & CACCTTCGAGCACCAGGGCACGGGCGTG \\
gB Ka N700Q F & CGCGGGTGACCCTGCAGCTGACGCTGCTGG \\
130 & CGTGCCCGTCCCCGTGCAGGAGATC \\
134 & CCATCTACCGGCGGCGCTACAACAG \\
\hline
\end{tabular}

Only forward strand mutagenesis primers (F) are listed. The corresponding reverse strand primers are ex actly complementary. PrV gB residues are numbered according to GenBank accession number EM64049.1 [64]. Nonmatching nucleotides are shown in boldface.

\subsection{Western Blot Analyses}

RK13 cells were harvested $24 \mathrm{~h}$ after transfection with $600 \mathrm{ng}$ of the expression plasmids encoding wild-type $\mathrm{gB}$ or the different $\mathrm{N}$-glycosylation mutants using lipofectamine 2000 (Thermo Fisher Scientific, Darmstadt, Germany). Cells were lysed, and protein samples were separated by discontinuous sodium dodecyl sulfate-polyacrylamide gel electrophoresis (SDS-PAGE) and transferred to nitrocellulose membranes. Membranes were incubated with monoclonal $\operatorname{PrV}$ gB antibodies (c15-b1 or A20-c26 at 1:10 dilution) [18,47] and peroxidase-conjugated secondary antibody (Dianova, Hamburg, Germany). Clarity Western ECL substrate (Bio-Rad Laboratories, Feldkirchen, Germany) and a VersaDoc 4000 MP imager (Bio-Rad Laboratories, Feldkirchen, Germany) were used for detection.

\subsection{PNGase F Digestion for Glycosylation Analysis}

Lysates of RK13 cells transfected with expression plasmids for WT gB or gB-N6xQ were treated with $500 \mathrm{U}$ of peptide-N-glycosidase $\mathrm{F}$ (PNGase) for $2 \mathrm{~h}$ at $37^{\circ} \mathrm{C}$ under buffer conditions according to manufacturer's instructions to remove all N-linked glycans. After digestion, samples were separated by SDS-PAGE as described above.

\subsection{In Vitro Cell-Cell Fusion Assays}

Fusion activity of the $\mathrm{gB} \mathrm{N}$-glycosylation site mutants was determined using a transient transfection-based cell-cell fusion assay [44]. Briefly, approximately $1.8 \times 10^{5}$ RK13 cells per well were seeded into 24-well cell culture plates and transfected with $200 \mathrm{ng}$ each of the expression plasmids for EGFP (pEGFP-N1; Clontech), PrV gH, gL, gD and WT gB or the different N-glycosylation site gB mutants in $100 \mu \mathrm{L}$ of Opti-MEM using $1 \mu \mathrm{L}$ of lipofectamine 2000 (Thermo Fisher Scientific, Düsseldorf, Germany). Twenty-four hours post-transfection, cells were fixed with $3 \%$ paraformaldehyde, and syncytium formation was assessed using an Eclipse Ti-S fluorescence microscope and NIS-Elements imaging software (Nikon, Düsseldorf, Germany). Total fusion activity was determined by multiplication of the number of syncytia with three or more nuclei by the mean syncytia area within 10 fields of view ( $5.5 \mathrm{~mm}^{2}$ each). Mean values and standard deviations from four independent assays were determined. 


\subsection{Trans-Complementation Assay}

The ability of the different gB mutants to function in virus entry was determined by trans-complementation of $\operatorname{PrV}-\Delta \mathrm{gB}$ [47] as described previously [18]. Briefly, approximately $1.8 \times 10^{5}$ RK13 cells per well were seeded into 24-well cell culture plates. On the following day, cells were transfected with $400 \mathrm{ng}$ of the expression plasmid for WT or mutant gB using $1 \mu \mathrm{L}$ lipofectamine 2000. Twenty-four hours post-transfection, the cells were infected with phenotypically gB-complemented $\operatorname{PrV}-\Delta \mathrm{gB}$ at a multiplicity of infection (MOI) of 3 on ice and consecutively incubated $1 \mathrm{~h}$ on ice and at $37^{\circ} \mathrm{C}$ for $1 \mathrm{~h}$. Subsequently, the inoculum was removed, and the non-penetrated virus was inactivated by low- $\mathrm{pH}$ treatment [65]. Cells were washed with PBS, and $1 \mathrm{~mL}$ fresh prewarmed medium was added to the monolayer. After twenty-four hours at $37^{\circ} \mathrm{C}$, the cells were harvested together with the supernatants and lysed by freeze-thawing $\left(-80^{\circ} \mathrm{C}\right.$ and $\left.37^{\circ} \mathrm{C}\right)$. Progeny virus titers were determined on RK13-gB cells. The experiment was repeated four times, and mean values and corresponding standard deviations were calculated.

\subsection{Comparative Indirect Immunofluorescence Analysis}

To visualize total and surface localization of the gB mutants, comparative indirect immunofluorescence analyses of transfected and permeabilized or non-permeabilized RK13 cells were done. RK13 cell monolayers in 24 well cell culture dishes were transfected with $400 \mathrm{ng}$ of the corresponding gB expression plasmids as described above (lipofectamine 2000; Thermo Fisher Scientific, Darmstadt, Germany). Twenty-four hours post-transfection, cells were fixed with $3 \%$ PFA in PBS for $20 \mathrm{~min}$. Optionally, cells were permeabilized in PBS containing $0.1 \%$ Triton X-100 for $10 \mathrm{~min}$ at room temperature. Subsequently, all cells were washed with PBS and blocked with $0.25 \%$ skimmed milk in PBS before they were incubated with the rabbit antiserum specific for $\operatorname{PrV} \mathrm{gB}$ at a dilution of 1:1000 in PBS [48]. After $1 \mathrm{~h}$ at room temperature, bound antibody was detected with Alexa 488- or 633-conjugated goat anti-rabbit antibodies (Thermo Fisher Scientific, Darmstadt, Germany) at a dilution of 1:1000 in PBS. Nuclei were stained with Hoechst (33,342 staining dye solution; Abcam, Berlin, Germany) at a dilution of 1:20,000 in PBS for $10 \mathrm{~min}$ at room temperature. Representative images were taken with a Leica DMi8 fluorescence microscope (Leica Microsystems, Wetzlar, Germany).

Author Contributions: Conceptualization, M.V., B.G.K. and T.C.M.; formal analysis, M.V.; funding acquisition, B.G.K. and T.C.M.; investigation, M.V.; methodology, M.V.; supervision, B.G.K. and T.C.M.; writing-original draft, M.V.; writing-review and editing, M.V., B.G.K. and T.C.M. All authors have read and agreed to the published version of the manuscript.

Funding: This research was funded by the Deutsche Forschungsgemeinschaft, DFG grant number Me 854/11-2.

Institutional Review Board Statement: Not applicable.

Informed Consent Statement: Not applicable.

Data Availability Statement: Data are contained within the article.

Acknowledgments: The technical assistance of K. Müller is greatly appreciated.

Conflicts of Interest: The authors declare no conflict of interest. The funders had no role in the design of the study; in the collection, analyses, or interpretation of data; in the writing of the manuscript, or in the decision to publish the results.

\section{References}

1. Davison, A.J. Herpesvirus Systematics. Vet. Microbiol. 2010, 143, 52-69. [CrossRef]

2. Mettenleiter, T.C. Pseudorabies Virus. In Encyclopedia of Virology; Mahy, B.W.J., Van Regenmortel, M.H.V., Eds.; Elsevier: Oxford, UK, 2008; pp. 341-351.

3. Sehl, J.; Teifke, J.P. Comparative Pathology of Pseudorabies in Different Naturally and Experimentally Infected Species-a Review. Pathogens 2020, 9, 633. [CrossRef]

4. Harrison, S.C. Viral Membrane Fusion. Virology 2015, 479-480, 498-507. [CrossRef] 
5. Vallbracht, M.; Backovic, M.; Klupp, B.G.; Rey, F.A.; Mettenleiter, T.C. Common Characteristics and Unique Features: A Comparison of the Fusion Machinery of the Alphaherpesviruses Pseudorabies Virus and Herpes Simplex Virus. Adv. Virus Res. 2019, 104, 225-281.

6. Spear, P.G.; Longnecker, R. Herpesvirus Entry: An Update. J. Virol. 2003, 77, 10179-10185. [CrossRef]

7. Connolly, S.A.; Jackson, J.O.; Jardetzky, T.S.; Longnecker, R. Fusing Structure and Function: A Structural View of the Herpesvirus Entry Machinery. Nat. Rev. Microbiol. 2011, 9, 369-381. [CrossRef]

8. Krummenacher, C.; Carfi, A.; Eisenberg, R.J.; Cohen, G.H. Entry of Herpesviruses into Cells: The Enigma Variations. Adv. Exp. Med. Biol. 2013, 790, 178-195.

9. Atanasiu, D.; Saw, W.T.; Cohen, G.H.; Eisenberg, R.J. Cascade of Events Governing Cell-Cell Fusion Induced by Herpes Simplex Virus Glycoproteins Gd, Gh/Gl, and Gb. J. Virol. 2010, 84, 12292-12299. [CrossRef]

10. Atanasiu, D.; Whitbeck, J.C.; Cairns, T.M.; Reilly, B.; Cohen, G.H.; Eisenberg, R.J. Bimolecular Complementation Reveals That Glycoproteins Gb and Gh/Gl of Herpes Simplex Virus Interact with Each Other During Cell Fusion. Proc. Natl. Acad. Sci. USA 2007, 104, 18718-18723. [CrossRef]

11. Stampfer, S.D.; Heldwein, E.E. Stuck in the Middle: Structural Insights into the Role of the Gh/Gl Heterodimer in Herpesvirus Entry. Curr. Opin Virol. 2013, 3, 13-19. [CrossRef]

12. Geraghty, R.J.; Krummenacher, C.; Cohen, G.H.; Eisenberg, R.J.; Spear, P.G. Entry of Alphaherpesviruses Mediated by Poliovirus Receptor-Related Protein 1 and Poliovirus Receptor. Science 1998, 280, 1618-1620. [CrossRef] [PubMed]

13. Montgomery, R.I.; Warner, M.S.; Lum, B.J.; Spear, P.G. Herpes Simplex Virus-1 Entry into Cells Mediated by a Novel Member of the Tnf/Ngf Receptor Family. Cell 1996, 87, 427-436. [CrossRef]

14. Cairns, T.M.; Atanasiu, D.; Saw, W.T.; Lou, H.; Whitbeck, J.C.; Ditto, N.T.; Bruun, B.; Browne, H.; Bennett, L.; Wu, C.; et al. Localization of the Interaction Site of Herpes Simplex Virus Glycoprotein D (Gd) on the Membrane Fusion Regulator, Gh/Gl. J. Virol. 2020, 94, e00983-20. [CrossRef] [PubMed]

15. Eisenberg, R.J.; Atanasiu, D.; Cairns, T.M.; Gallagher, J.R.; Krummenacher, C.; Cohen, G.H. Herpes Virus Fusion and Entry: A Story with Many Characters. Viruses 2012, 4, 800-832. [CrossRef]

16. Atanasiu, D.; Whitbeck, J.C.; de Leon, M.P.; Lou, H.; Hannah, B.P.; Cohen, G.H.; Eisenberg, R.J. Bimolecular Complementation Defines Functional Regions of Herpes Simplex Virus Gb That Are Involved with Gh/Gl as a Necessary Step Leading to Cell Fusion. J. Virol. 2010, 84, 3825-3834. [CrossRef]

17. Rogalin, H.B.; Heldwein, E.E. Interplay between the Herpes Simplex Virus 1 Gb Cytodomain and the Gh Cytotail During Cell-Cell Fusion. J. Virol. 2015, 89, 12262-12272. [CrossRef]

18. Vallbracht, M.; Brun, D.; Tassinari, M.; Vaney, M.C.; Pehau-Arnaudet, G.; Guardado-Calvo, P.; Haouz, A.; Klupp, B.G.; Mettenleiter, T.C.; Rey, F.A.; et al. Structure-Function Dissection of the Pseudorabies Virus Glycoprotein B Fusion Loops. J. Virol. 2018, 92, e01203-17. [CrossRef]

19. Li, X.; Yang, F.; Hu, X.; Tan, F.; Qi, J.; Peng, R.; Wang, M.; Chai, Y.; Hao, L.; Deng, J.; et al. Two Classes of Protective Antibodies against Pseudorabies Virus Variant Glycoprotein B: Implications for Vaccine Design. PLoS Pathog. 2017, 13, e1006777. [CrossRef]

20. Heldwein, E.E.; Lou, H.; Bender, F.C.; Cohen, G.H.; Eisenberg, R.J.; Harrison, S.C. Crystal Structure of Glycoprotein B from Herpes Simplex Virus 1. Science 2006, 313, 217-220. [CrossRef]

21. Oliver, S.L.; Xing, Y.; Chen, D.H.; Roh, S.H.; Pintilie, G.D.; Bushnell, D.A.; Sommer, M.H.; Yang, E.; Carfi, A.; Chiu, W.; et al. A Glycoprotein B-Neutralizing Antibody Structure at 2.8 a Uncovers a Critical Domain for Herpesvirus Fusion Initiation. Nat. Commun. 2020, 11, 4141. [CrossRef]

22. Backovic, M.; Jardetzky, T.S. Class Iii Viral Membrane Fusion Proteins. Adv. Exp. Med. Biol. 2011, 714, 91-101. [PubMed]

23. Fontana, J.; Atanasiu, D.; Saw, W.T.; Gallagher, J.R.; Cox, R.G.; Whitbeck, J.C.; Brown, L.M.; Eisenberg, R.J.; Cohen, G.H. The Fusion Loops of the Initial Prefusion Conformation of Herpes Simplex Virus 1 Fusion Protein Point toward the Membrane. MBio 2017, 8, e01268-17. [CrossRef] [PubMed]

24. Vollmer, B.; Prazak, V.; Vasishtan, D.; Jefferys, E.E.; Hernandez-Duran, A.; Vallbracht, M.; Klupp, B.G.; Mettenleiter, T.C.; Backovic, M.; Rey, F.A.; et al. The Prefusion Structure of Herpes Simplex Virus Glycoprotein B. Sci. Adv. 2020, 6, eabc1726. [CrossRef] [PubMed]

25. Si, Z.; Zhang, J.; Shivakoti, S.; Atanasov, I.; Tao, C.L.; Hui, W.H.; Zhou, K.; Yu, X.; Li, W.; Luo, M.; et al. Different Functional States of Fusion Protein Gb Revealed on Human Cytomegalovirus by Cryo Electron Tomography with Volta Phase Plate. PLoS Pathog. 2018, 14, e1007452. [CrossRef]

26. Waterhouse, A.; Bertoni, M.; Bienert, S.; Studer, G.; Tauriello, G.; Gumienny, R.; Heer, F.T.; de Beer, T.A.P.; Rempfer, C.; Bordoli, L.; et al. Swiss-Model: Homology Modelling of Protein Structures and Complexes. Nucleic Acids Res. 2018, 46, W296-W303. [CrossRef]

27. Goddard, T.D.; Huang, C.C.; Meng, E.C.; Pettersen, E.F.; Couch, G.S.; Morris, J.H.; Ferrin, T.E. Ucsf Chimerax: Meeting Modern Challenges in Visualization and Analysis. Protein. Sci. 2018, 27, 14-25. [CrossRef]

28. Watanabe, Y.; Bowden, T.A.; Wilson, I.A.; Crispin, M. Exploitation of Glycosylation in Enveloped Virus Pathobiology. Biochim. Biophys. Acta Gen. Subj. 2019, 1863, 1480-1497. [CrossRef]

29. Luo, S.; Hu, K.; He, S.; Wang, P.; Zhang, M.; Huang, X.; Du, T.; Zheng, C.; Liu, Y.; Hu, Q. Contribution of N-Linked Glycans on Hsv-2 Gb to Cell-Cell Fusion and Viral Entry. Virology 2015, 483, 72-82. [CrossRef] 
30. Vallbracht, M.; Rehwaldt, S.; Klupp, B.G.; Mettenleiter, T.C.; Fuchs, W. Functional Role of N-Linked Glycosylation in Pseudorabies Virus Glycoprotein Gh. J. Virol. 2018, 92, e00084-18. [CrossRef]

31. Kornfeld, R.; Kornfeld, S. Assembly of Asparagine-Linked Oligosaccharides. Annu. Rev. Biochem. 1985, 54, 631-664. [CrossRef]

32. Helenius, A.; Aebi, M. Roles of N-Linked Glycans in the Endoplasmic Reticulum. Annu. Rev. Biochem. 2004, 73, 1019-1049. [CrossRef] [PubMed]

33. Lee, P.S.; Ohshima, N.; Stanfield, R.L.; Yu, W.; Iba, Y.; Okuno, Y.; Kurosawa, Y.; Wilson, I.A. Receptor Mimicry by Antibody F045-092 Facilitates Universal Binding to the H3 Subtype of Influenza Virus. Nat. Commun. 2014, 5, 3614. [CrossRef] [PubMed]

34. Kobayashi, Y.; Suzuki, Y. Evidence for N-Glycan Shielding of Antigenic Sites During Evolution of Human Influenza a Virus Hemagglutinin. J. Virol. 2012, 86, 3446-3451. [CrossRef]

35. Grant, O.C.; Montgomery, D.; Ito, K.; Woods, R.J. Analysis of the Sars-Cov-2 Spike Protein Glycan Shield Reveals Implications for Immune Recognition. Sci. Rep. 2020, 10, 14991. [CrossRef] [PubMed]

36. Watanabe, Y.; Allen, J.D.; Wrapp, D.; McLellan, J.S.; Crispin, M. Site-Specific Glycan Analysis of the Sars-Cov-2 Spike. Science 2020, 369, 330-333. [CrossRef] [PubMed]

37. Walls, A.C.; Tortorici, M.A.; Frenz, B.; Snijder, J.; Li, W.; Rey, F.A.; DiMaio, F.; Bosch, B.J.; Veesler, D. Glycan Shield and Epitope Masking of a Coronavirus Spike Protein Observed by Cryo-Electron Microscopy. Nat. Struct. Mol. Biol. 2016, $23,899-905$. [CrossRef]

38. Xiong, X.; Tortorici, M.A.; Snijder, J.; Yoshioka, C.; Walls, A.C.; Li, W.; McGuire, A.T.; Rey, F.A.; Bosch, B.J.; Veesler, D. Glycan Shield and Fusion Activation of a Deltacoronavirus Spike Glycoprotein Fine-Tuned for Enteric Infections. J. Virol. 2018, 92, JVI.01628-17. [CrossRef]

39. Wang, B.; Wang, Y.; Frabutt, D.A.; Zhang, X.; Yao, X.; Hu, D.; Zhang, Z.; Liu, C.; Zheng, S.; Xiang, S.H.; et al. Mechanistic Understanding of N-Glycosylation in Ebola Virus Glycoprotein Maturation and Function. J. Biol. Chem. 2017, 292, 5860-5870. [CrossRef]

40. Panico, M.; Bouche, L.; Binet, D.; O’Connor, M.J.; Rahman, D.; Pang, P.C.; Canis, K.; North, S.J.; Desrosiers, R.C.; Chertova, E.; et al. Mapping the Complete Glycoproteome of Virion-Derived Hiv-1 Gp120 Provides Insights into Broadly Neutralizing Antibody Binding. Sci. Rep. 2016, 6, 32956. [CrossRef]

41. Cao, L.; Pauthner, M.; Andrabi, R.; Rantalainen, K.; Berndsen, Z.; Diedrich, J.K.; Menis, S.; Sok, D.; Bastidas, R.; Park, S.R.; et al. Differential Processing of Hiv Envelope Glycans on the Virus and Soluble Recombinant Trimer. Nat. Commun. 2018, 9, 3693. [CrossRef]

42. Fontes-Garfias, C.R.; Shan, C.; Luo, H.; Muruato, A.E.; Medeiros, D.B.A.; Mays, E.; Xie, X.; Zou, J.; Roundy, C.M.; Wakamiya, M.; et al. Functional Analysis of Glycosylation of Zika Virus Envelope Protein. Cell Rep. 2017, 21, 1180-1190. [CrossRef] [PubMed]

43. Mondotte, J.A.; Lozach, P.Y.; Amara, A.; Gamarnik, A.V. Essential Role of Dengue Virus Envelope Protein N Glycosylation at Asparagine-67 During Viral Propagation. J. Virol. 2007, 81, 7136-7148. [CrossRef]

44. Vallbracht, M.; Schröter, C.; Klupp, B.G.; Mettenleiter, T.C. Transient Transfection-Based Fusion Assay for Viral Proteins. BioProtocol 2017, 7, e2162. [CrossRef]

45. Whealy, M.E.; Robbins, A.K.; Enquist, L.W. The Export Pathway of the Pseudorabies Virus Gb Homolog Gii Involves Oligomer Formation in the Endoplasmic Reticulum and Protease Processing in the Golgi Apparatus. J. Virol. 1990, 64, 1946-1955. [CrossRef]

46. Wolfer, U.; Kruft, V.; Sawitzky, D.; Hampl, H.; Wittmann-Liebold, B.; Habermehl, K.O. Processing of Pseudorabies Virus Glycoprotein Gii. J. Virol. 1990, 64, 3122-3125. [CrossRef] [PubMed]

47. Nixdorf, R.; Klupp, B.G.; Karger, A.; Mettenleiter, T.C. Effects of Truncation of the Carboxy Terminus of Pseudorabies Virus Glycoprotein B on Infectivity. J. Virol. 2000, 74, 7137-7145. [CrossRef] [PubMed]

48. Kopp, M.; Granzow, H.; Fuchs, W.; Klupp, B.G.; Mundt, E.; Karger, A.; Mettenleiter, T.C. The Pseudorabies Virus Ul11 Protein Is a Virion Component Involved in Secondary Envelopment in the Cytoplasm. J. Virol. 2003, 77, 5339-5351. [CrossRef]

49. Bagdonaite, I.; Wandall, H.H. Global Aspects of Viral Glycosylation. Glycobiology 2018, 28, 443-467. [CrossRef]

50. Okazaki, K. Proteolytic Cleavage of Glycoprotein B Is Dispensable for in Vitro Replication, but Required for Syncytium Formation of Pseudorabies Virus. J. Gen. Virol. 2007, 88, 1859-1865. [CrossRef]

51. Dong, S.; Blissard, G.W. Functional Analysis of the Autographa Californica Multiple Nucleopolyhedrovirus Gp64 Terminal Fusion Loops and Interactions with Membranes. J. Virol. 2012, 86, 9617-9628. [CrossRef]

52. Strive, T.; Borst, E.; Messerle, M.; Radsak, K. Proteolytic Processing of Human Cytomegalovirus Glycoprotein B Is Dispensable for Viral Growth in Culture. J. Virol. 2002, 76, 1252-1264. [CrossRef]

53. Fan, Z.; Grantham, M.L.; Smith, M.S.; Anderson, E.S.; Cardelli, J.A.; Muggeridge, M.I. Truncation of Herpes Simplex Virus Type 2 Glycoprotein B Increases Its Cell Surface Expression and Activity in Cell-Cell Fusion, but These Properties Are Unrelated. J. Virol. 2002, 76, 9271-9283. [CrossRef]

54. Mettenleiter, T.C.; Spear, P.G. Glycoprotein Gb (Gii) of Pseudorabies Virus Can Functionally Substitute for Glycoprotein Gb in Herpes Simplex Virus Type 1. J. Virol. 1994, 68, 500-504. [CrossRef]

55. Böhm, S.W.; Backovic, M.; Klupp, B.G.; Rey, F.A.; Mettenleiter, T.C.; Fuchs, W. Functional Characterization of Glycoprotein H Chimeras Composed of Conserved Domains of the Pseudorabies Virus and Herpes Simplex Virus 1 Homologs. J. Virol. 2016, 90, 421-432. [CrossRef]

56. Stanley, P.; Schachter, H.; Taniguchi, N. N-Glycans. In Essentials of Glycobiology; Cold Spring Harbor: Suffolk County, NY, USA, 2009. 
57. Bieberich, E. Synthesis, Processing, and Function of N-Glycans in N-Glycoproteins. Adv. Neurobiol. 2014, 9, 47-70.

58. Berndsen, Z.T.; Chakraborty, S.; Wang, X.; Cottrell, C.A.; Torres, J.L.; Diedrich, J.K.; Lopez, C.A.; Yates, J.R., 3rd; van Gils, M.J.; Paulson, J.C.; et al. Visualization of the Hiv-1 Env Glycan Shield across Scales. Proc. Natl. Acad. Sci. USA 2020, 117, 28014-28025. [CrossRef]

59. Sodora, D.L.; Cohen, G.H.; Eisenberg, R.J. Influence of Asparagine-Linked Oligosaccharides on Antigenicity, Processing, and Cell Surface Expression of Herpes Simplex Virus Type 1 Glycoprotein D. J. Virol. 1989, 63, 5184-5193. [CrossRef]

60. Sodora, D.L.; Cohen, G.H.; Muggeridge, M.I.; Eisenberg, R.J. Absence of Asparagine-Linked Oligosaccharides from Glycoprotein D of Herpes Simplex Virus Type 1 Results in a Structurally Altered but Biologically Active Protein. J. Virol. 1991, 65, $4424-4431$. [CrossRef]

61. Sodora, D.L.; Eisenberg, R.J.; Cohen, G.H. Characterization of a Recombinant Herpes Simplex Virus Which Expresses a Glycoprotein D Lacking Asparagine-Linked Oligosaccharides. J. Virol. 1991, 65, 4432-4441. [CrossRef]

62. Kaplan, A.S.; Vatter, A.E. A Comparison of Herpes Simplex and Pseudorabies Viruses. Virology 1959, 7, 394-407. [CrossRef]

63. Klupp, B.G.; Nixdorf, R.; Mettenleiter, T.C. Pseudorabies Virus Glycoprotein M Inhibits Membrane Fusion. J. Virol. 2000, 74, 6760-6768. [CrossRef]

64. Szpara, M.L.; Tafuri, Y.R.; Parsons, L.; Shamim, S.R.; Verstrepen, K.J.; Legendre, M.; Enquist, L.W. A Wide Extent of Inter-Strain Diversity in Virulent and Vaccine Strains of Alphaherpesviruses. PLoS Pathog. 2011, 7, e1002282. [CrossRef]

65. Mettenleiter, T.C. Glycoprotein Giii Deletion Mutants of Pseudorabies Virus Are Impaired in Virus Entry. Virology 1989, 171, 623-625. [CrossRef] 